\title{
El folclore en la prensa romántica
}

Al poco tiempo de morir Fernando VII la actividad cultural experimenta un gran impulso, y eso a pesar de abrirse inmediatamente la Guerra de los Siete Años. Diversas causas originan este renacimiento: la misma muerte del rey absoluto, que determina una mayor libertad, si bien más cultural que política; el vigor que tiene en esos años el romanticismo, recién entrado en España, y cuyos partidarios están deseosos de remover el ambiente cultural; y, aunque parezca paradójico, la guerra carlista. Más de una revista justifica la proliferación de publicaciones culturales por la necesidad que tienen los españoles de contrarrestar con los frutos del espíritu las amarguras de la guerra; una manera de distraer los duelos.

Los pocos medios y los pocos suscriptores con que cuentan las revistas condicionan su existencia, durando generalmente dos o tres años, aunque muchas hay que no llegan al año. Especialmente en la década de los cuarenta se produce una invasión de revistas literarias, y no sólo en los grandes núcleos de población, aunque tengan que cerrar a los pocos meses.

Claro indicio de la pujanza de la actividad cultural es la creación, primero en Madrid pero después por toda España, de ateneos y liceos, algunos de ellos con revista como órgano de la institución.

La mayor parte del espacio lo ocupan las revistas en la creación literaria (cuento, novela, poesía) y en la crítica literaria. Tienen además su sitio la historia, la geografía, los viajes y las noticias de la actualidad cultural, especialmente los estrenos teatrales.

El estudio de la cultura popular en esos años suscita aún poco interés, y desde luego está muy lejos de la atención que se le prestará medio siglo después.

\section{Madrid}

El Semanario Pintoresco Español, que fundó en abril de 1836 Ramón de Mesonero, es la revista cultural de mayor prestigio en los años centrales del siglo XIX. Indicativo de la buena acogida que tuvo fueron los veintiún años que duró la publicación. 
De los tres primeros años sólo podemos consignar el artículo anónimo "Tonadas nacionales de diferentes países", que hace un breve recuento de canciones populares, extranjeras y españolas (seguidilla, bolero, fandango, tirana). Otros artículos sobre fiestas, costumbres, leyendas, son puramente literarios.

En 1839 sí hay una serie de interés: "Usos y trajes provinciales", en donde se escribe de cantos, bailes, festejos, creencias populares, vestimentas regionales. Entre los autores hay dos firmas estelares: Miguel Agustín Príncipe, que escribe sobre sus paisanos de Aragón, y Enrique Gil y Carrasco, sobre pasiegos, asturianos y leoneses. Textos tan bien escritos como cabe suponer de la calidad de estas dos plumas. Además, una amplia serie de cinco artículos sobre costumbres vascongadas, de Antonio de Iza Zamácola, y trabajos sobre gallegos, valencianos... En 1840 siguió la serie.

Fuera de esta colección costumbrista, aparece en 1839 un artículo sobre las fiestas de Santa Águeda en Zamarramala, y otro sobre los Moros y Cristianos de Valencia. De los siguientes años lo que tiene mayor interés son las descripciones de fiestas, sagradas o profanas.

Si el romanticismo se identifica con alguna revista en concreto, ésta es indudablemente $\mathrm{El} \mathrm{Artista}$ que se publica en los años 1835 y 1836 . El semanario fue dirigido por Eugenio de Ochoa y Pedro Madrazo. La principal objeción que se puede poner al lindísimo portavoz del romanticismo es la excesiva presencia de sus directores, sobre todo Ochoa; hay números que escribe prácticamente él solo.

En El Artista aparece una colección de artículos sobre costumbres populares españolas que firma el otro Ochoa, José Augusto de Ochoa. Escribe tres sobre fiestas (San Juan, San Sebastián, Día de Todos los Santos) y dos sobre la celebración de los velatorios y de las honras fúnebres, casi todo referido a la provincia de Jaén. Su visión de las formas de comportamiento del pueblo no puede ser más negativa: todo es borrachera, disipación. Hablando de la celebración del Día de Todos los Santos, concluye con estas palabras, que nos indican claramente cuál es su criterio: "Este día de dolorosos recuerdos es día de tumulto y de disipación, y de ningún respeto a la calidad y dignidad de las personas. Así son todas las diversiones populares en España; nada se respeta, todo se mancha, todo se atropellan.

En las honras fúnebres, el luto y la tristeza de la manana dejan paso a una alegría desenfrenada en el transcurso de una gran comilona, que termina en una batalla campal. Y el autor condena: "Escena escandalosa, orgía infernal, origen de mil vicios, y cuyos resultados son tan notoriamente dañosos, que cuantas reflexiones podamos hacer son inútiles". Y de este tenor son las demás valoraciones que hace José Augusto de Ochoa. 
También escribe él mismo en El Artista tres casos de supersticiones populares, con la brujería como protagonista, y dos leyendas: "Beltrán" y "El torrente de Blanca".

El Laberinto se publica entre 1843 y 1845 . Estuvo dirigido, primero, por el escritor costumbrista Antonio Flores y después por el crítico literario y poeta Antonio Ferrer del Río. El editor y propietario es el prestigioso Ignacio Boix, el más exquisito de la época.

Naturalmente, destacan los artículos costumbristas de Flores; la mayoría de ellos no atañen a la cultura popular, pero alguno hay sobre fiestas y celebraciones populares: "Todo Madrid en San Isidro", en el que habla de la Pradera; "El Carnaval de Madrid", en el que trata del baile, de las máscaras, del entierro de la sardina, etc; y "Las verbenas", que aunque lo titula en plural se refiere sólo a la de San Antonio de la Florida.

Aparte de los textos de Flores, se incluye el artículo anónimo "Noticias acerca del baile", una parte del cual está dedicado a los bailes populares españoles; dos canciones, puestas en música, del compositor de aires populares Mariano Soriano Fuentes; y "El paso-honroso", de José Amador de los Ríos, tradición que ya había publicado en la revista sevillana El Cisne.

De $E l$ Reflejo, que se publicaba en el año 1843, destacamos el trabajo de Amelia Corradi, "Los novios en Sanlúcar". Señala que las gentes del pueblo "son las únicas que tienen alguna originalidad, pues la clase alta, las personas que tienen el título de gente de sangre azul son ni más ni menos que en todos los pueblos de provincia: vanidosas, amigas de chismografía, sin pasear ni hacer visitas más que los días de fiesta, y llenas de preocupaciones y puerilidades necias".

Lo que narra Corradi son las fiestas de los domingos por la tarde en una casa particular, fiesta en la que tiene papel preeminente el fandango. Es interesante para conocer el folclore andaluz emparentado con el flamenco en sus orígenes.

Vicente Castelló funda en $1845 \mathrm{El}$ Siglo Pintoresco, que se mantiene hasta 1848. Hay artículos sobre costumbres y tipos populares firmados por su director, Francisco Navarro Villoslada, y por Ángel Fernández de los Ríos y "El Solitario". El de más interés folclórico es "Asamblea general de los Caballeros y Damas de Triana", de "El Solitario" (o sea, Estébanez Calderón), texto clásico y de referencia necesaria en los estudios sobre el arte flamenco.

Leyendas históricas, más o menos populares, se encuentran en otras revistas, como La Mariposa o El Ramillete; recordemos que en esos años el tema histórico es muy importante tanto en la novela como en el drama. 


\section{Valencia}

La gran revista valenciana de los años cuarenta es El Fénix, que sale entre 1844 y 1847. La dirige Rafael Carvajal, y cuenta en la redacción con el entonces prestigioso historiador y poeta Vicente Boix.

Los cuentos y leyendas populares están representados con "Visita al infierno", "Esperando la del cielo" (transcrita por Boix), "Los dos amantes", que es una tradición normanda, y "El lobo", leyenda bretona que narra un caso de licantropía. Peregrín García Cadena, Francisco de García López, "El curioso observador" y Amelia Corradi firman varios artículos costumbristas, como la celebración del carnaval o las "festes de carrer"; sobre tipos, como el estudiante o el contrabandista; y de bailes, uno sobre el bolero, con un gracioso grabado de Lola Montes bailando la cachucha, y otro titulado "Baile en un bodegón a las afueras de Madrid", que firma García López, importante para los que deseen conocer cómo era el flamenco en sus primeros tiempos.

Por lo que supone de defensa del folclore hay que destacar el artículo de Antonio Neira de Mosquera "Canciones populares", publicado el 3 de mayo de 1846. Reivindica el valor de estas producciones y anima a que las estudien los musicólogos y los críticos literarios:

Estas canciones populares, respetadas por el transcurso del tiempo, porque pertenecen al lenguaje del corazón, y que representan fiel y exactamente la índole especial de cada pueblo, deben ser justamente apreciadas por los inteligentes, y recogidas por un artista de ingenio, que, filósofo y práctico a la vez, presente de una vez las investigaciones de la historia y las originalidades de una música primitiva, sencilla y natural. Este trabajo reportaría al que lo tomase por su cuenta con fe y verdadera aplicación un grande título al reconocimiento de los profesores filarmónicos y al aprecio de los literatos estudiosos.

La revista La Perla comienza a publicarse el 6 de octubre de 1844, llamándose La Esmeralda a partir del 15 de diciembre; concluye en enero de 1848.

Lo más notable de La Esmeralda son algunos artículos dedicados a las fiestas. Francisco Puig y Pascual describe la celebración del Corpus, la romería de Nuestra Señora de la Salud y las "festes de carrer", que retratan, según Puig, el carácter de la sociedad valenciana: "No es la primera vez [que] se nos ha echado en cara por personas de mucho valer que por grandes y dolorosos recuerdos que abrigase el pueblo valenciano, se han disipado como el humo tan pronto como han oído el tambor y la dulzaina. Esta fama proverbial la tenemos muy bien sentada, y donde más resalta es en las tan celebradas fiestas de callew. 
El propio Puig dedica un artículo al dulzainero, músico ambulante que es el alma de las fiestas. También escribe semblanzas de tipos valencianos, sin especial interés, y de costumbres típicas, como la tradición pascual de la mona.

Francisco de Paula Gras firma la sección "Panorama de las costumbres valencianas", en la que hay artículos sobre las fallas y sobre la fiesta de los milagros, que consiste en representaciones de los milagros de San Vicente Ferrer.

La Esmeralda incluye dos leyendas populares, aunque ninguna valenciana: "La mora encantada", historia aragonesa de los tiempos de la dominación árabe, y "El abad Duncanius", tradición germana del siglo XII, que narra la tentación que sufre el abad por instigación del Maligno, y su consiguiente caída, a pesar de su fama de santo.

\section{Canarias}

En los años 1897 y 1898 sale en Santa Cruz de Tenerife una de las más interesantes revistas literarias románticas: La Aurora. Buena parte de los asuntos que trata está relacionada con Canarias, circunstancia más normal que en otras regiones dada su insularidad y el olvido por parte de la España peninsular.

En el apartado de "Costumbres" varios trabajos merecen la atención: un artículo sobre la lucha canaria, de la que dice el anónimo redactor que es "una de las pocas costumbres que las generaciones conquistadoras han conservado de los antiguos canarios"; otro, sobre el tango que se bailaba en Hierro, y que conservaba la antigua forma que usaban los guanches; y otro, describiendo la fiesta del Pilar que se celebra en Santa Cruz, con una curiosa armonía de valses y pasodobles mezclados con cantos y bailes indígenas, como el tagaraste, la folía y la upalaja.

Tres son las leyendas tradicionales que incluye: "La reina Fayna", "Guadarfe, ojo de cuervo" y "La cuesta de los Habares", las dos primeras pertenecientes al periodo anterior a la colonización española; la tercera, transcrita por José Desiré Dugour, es una preciosa historia de enamorados.

La Aurora recoge una intervención del etnógrafo francés Sabino Berthelot en la Sociedad Geográfica de París sobre los antiguos habitantes de las Islas Afortunadas. En números sucesivos traduce el folleto de Berthelot, Memoria sobre el origen de los guanches.

En el concepto genérico de "Variedades" hay varios trabajos de tipo costumbrista o folclórico, unos anónimos y otros firmados por Dugour: 
"La fiesta de San Pedro en Güímar", "Los compadres", "Escenas carnavalescas", "El aprendiz de novio", "El costero", etc.

\section{Andalucía}

De las muchas revistas que salen en Andalucía en los años treinta y cuarenta, la más interesante para nuestro objeto es la malagueña $E l$ Guadalhorce, que se publica en 1839 y 1840.

Pedro Gómez Sancho escribe en El Guadalhorce una serie sobre costumbres populares del lugar y sus tipos: el charrán, la vendeja, el caballista, la nochebuena, el guarda de camino... José María Bremón hace una poética glosa de la rondeña, y reelabora en verso la leyenda popular "La peña de los Enamorados", tema muy tratado en esos años del romanticismo (incluso Aureliano Fernández Guerra estrena en 1839 un drama con este asunto). Utilizando el tipo del contrabandista, Ildefonso Marzo escribe la narración costumbrista "Venga de ahí". Firmada con el seudónimo de "El Andaluz", se recrea la leyenda rondeña "El castillo de Benadalid", que data de la Reconquista.

A los románticos siembre les pareció mal la invasión de tantos modos, costumbres y culturas extranjeras, que iba en detrimento de lo nacional. Lamentando esa pérdida de identidad, dice un artículo de la revista, del 2 de junio de 1839:

\footnotetext{
No puede considerarse sin dolor el abandono en que van cayendo nuestras costumbres. La manía de vivir al uso de otros países se ha apoderado de tal manera de nosotros que afectamos la ignorancia de ellas, teniendo a mengua el practicar las que hemos alcanzado en nuestra infancia. [...] Despreciar una costumbre antigua porque no es positivamente útil, sería igual a demoler aquellos ruinosos pero venerables monumentos porque ocupan un terreno que pudiera producir algunas medidas de trigo.
}

Varias décadas duró La Moda, que empieza a publicarse en Cádiz en 1842, trasladándose a Madrid en 1870 . En su primera etapa, dirigida y casi redactada en su totalidad por Francisco Flores Arenas, hay dos artículos sobre bailes populares, el ole y el fandango, y una demoledora y burlesca crítica sobre el libro La tía Marizápalos, que recopila cuentos de magia y encantamiento. Buena acogida, no obstante, debió de tener la obra, ya que después de la primera edición de 1840 se hizo una segunda en 1843.

La Albambra, que se publica en Granada entre 1839 y 1843 , incluye también la leyenda "La peña de los Enamorados", además de otras narra- 
ciones de tipo histórico-popular, principalmente de la Granada árabe o morisca. Alguna se sale de esta línea, como "La torre de los siete suelos", firmada por Luis de Montes, que es un cuento de maravillas del siglo XviI.

Hay algunos textos más, como la transcripción de proverbios árabes o el consabido artículo sobre el contrabandista, en el que se citan dos coplas flamencas (cañas).

\section{Barcelona}

A pesar de las muchas revistas literarias que salen en los años cuarenta en Barcelona, el tema folclórico no tiene presencia. Rescatamos, como excepción, dos trabajos publicados en El Heraldo del año 1840. Uno de ellos, "Música popular y teatral", que incluye F. Fors de Casamayor dentro de la serie "Origen y progresos de la música en España", y en el que hace un brevísimo repaso histórico de juglares, jácaras y tonadillas; y otro, la leyenda "El arquitecto de la catedral de Colonia", que narra el pacto con el diablo que hizo el constructor.

EUGENIO COBO 